\title{
Reaction in photofuel cells using allophane-titania nanocomposite electrodes
}

\author{
Hiromasa Nishikiori ${ }^{1, *}$, Shun Hashiguchi ${ }^{1}$, Masaaki Ito ${ }^{1}$, Rudi Agus Setiawan ${ }^{1}$, Tsuneo Fujii ${ }^{2}$ \\ ${ }^{1}$ Department of Environmental Science and Technology, Faculty of Engineering, Shinshu University, \\ 4-17-1 Wakasato, Nagano 380-8553, Japan
}

${ }^{2}$ Nagano Prefectural Institute of Technology, 813-8 Shimonogo, Ueda, Nagano 386-1211, Japan

Corresponding author: Hiromasa Nishikiori

Tel: +81-26-269-5536

Fax: +81-26-269-5531

E-mail: nishiki@shinshu-u.ac.jp

Department of Environmental Science and Technology, Faculty of Engineering, Shinshu University,

4-17-1 Wakasato, Nagano 380-8553, Japan 


\begin{abstract}
Allophane-titania nanocomposite electrodes for photofuel cells were prepared from titanium alkoxide sols dispersing the natural clay mineral allophane. The electrochemical measurements indicated that the oxidative degradation of starch in the solutions and suspensions enhanced the generation of electricity during UV irradiation. $\mathrm{CO}_{2}$ was observed as the degradation product. A higher photocurrent was observed using the allophane-titania nanocomposite electrode adsorbing a greater amount of the starch molecules. Allophane increased the capacity of the electrode to adsorb the starch molecules, even from the suspensions. This brought the molecules close to the titania nanoparticles, on which their oxidation induced the generation of electricity.
\end{abstract}

Keywords: photocatalysis; photofuel cell; titania; allophane; starch 


\section{Introduction}

The electronic application of photocatalysts is developing in various fields such as photovoltaic cells due to their semiconducting properties. Photocatalyst titania films are widely studied as dye-sensitized solar cell electrodes and are approaching their practical use [1-3]. They are also useful as photofuel cell electrodes to generate electricity assisted by oxidizing the fuel materials during UV irradiation [4-9]. Photofuel cell is based on the mechanism of solar cell, in which the available energy depends on the conduction band potential of the semiconductor. In the solar cells using aqueous electrolyte solutions, electrons are circulated by water splitting and its reverse reaction. Such solar cells exhibit low photoelectric conversion efficiency due to the charge recombination and back electron transfer. The organic compounds added to the electrolyte solutions prevent the backward processes due to efficient consumption of the electrons and holes. Oxidative degradation of fuel materials promotes the electron circulation rather than generates electricity from their combustion energy. The photofuel cell electrodes generally act in the liquid phase containing the fuel material. In such systems, the concentration of the fuel material on the photocatalyst surface is one of the parameters for improving the energy conversion efficiency $[10,11]$. A method to increase the concentration is the use of the appropriate adsorbents.

A clay mineral, allophane, was reported to have a 3.5-5.0-nm-sized hollow spherical particle structure with $0.3-0.5$-nm-sized defects on its surface and a significant ability to adsorb ionic or polar chemicals due to their amphoteric ion-exchange activity and high surface area [12-17]. The claytitania composites are effective in degrading organic compounds [18-22] because the adsorbed molecules should be quickly brought to the titania surface [23]. However, hybridization of the general clay minerals with the photocatalysts decreased their photocatalytic activity because such clay minerals consist of relatively large-sized insulative particles. There is a possibility that the high dispersion of allophane nanoparticles on the photocatalyst surface allows retention of the semiconductivity and activity. 
We previously prepared allophane-titania nanocomposite thin films on the glass plates coated with ITO (Indium Tin Oxide) transparent electrodes as the working electrodes of the photofuel cells by the sol-gel method [24]. Electrochemical measurements indicated that the oxidative degradation of glucose in the electrolyte enhanced the generation of electricity during UV irradiation. A higher short circuit current was observed in the photofuel cell using the $0.10 \%$ allophane-containing titania electrode than that with the normal titania electrode. Allophane effectively adsorbed the glucose molecules and then brought them close to the titania nanoparticles, on which their oxidation induced the electrogeneration.

Such liquid phases are required to be highly concentrated solution or suspension of the fuel materials of slightly soluble polymers because the polymers originating from plant wastes are preferred for utilization as the materials. In this study, starch was used as a fuel material in order to evaluate the degradation reaction in its solutions and suspensions as the pre-stage using cellulose compounds. We investigated the photocatalytic oxidative degradation of the starch solutions and suspensions in the photofuel cells using allophane-titania nanocomposite electrodes and their energy conversion properties. The effect of the adsorption ability of allophane on the photofuel cell reactions was also examined.

\section{Experimental}

\subsection{Materials}

Ethanol $\left(\mathrm{C}_{2} \mathrm{H}_{5} \mathrm{OH}\right)$, titanium tetraisopropoxide $\left(\mathrm{Ti}\left(\mathrm{OCH}\left(\mathrm{CH}_{3}\right)_{2}\right)_{4}\right)$, nitric acid $\left(\mathrm{HNO}_{3}\right)$, hydrochloric acid $(\mathrm{HCl})$, sodium hydroxide $(\mathrm{NaOH})$, sodium carbonate $\left(\mathrm{Na}_{2} \mathrm{CO}_{3}\right)$, and methylene blue (MB, $\left.\mathrm{C}_{16} \mathrm{H}_{18} \mathrm{~N}_{3} \mathrm{SCl}\right)$ (Wako, $\mathrm{S}$ or reagent grade) and starch $\left(\left(\mathrm{C}_{6} \mathrm{H}_{10} \mathrm{O}_{5}\right)_{\mathrm{n}}\right)$ (Yoneyama, reagent grade) were used without further purification. The water was deionized and distilled. Glass plates coated with the ITO transparent electrode $(60 \mathrm{~mm} \times 25 \mathrm{~mm})$ (AGC Fabritec) were soaked in 
hydrochloric acid $\left(1.0 \mathrm{~mol} \mathrm{dm}^{-3}\right)$ for $1 \mathrm{~h}$ and then rinsed with water. The allophane $\left(1.6 \mathrm{SiO}_{2} \cdot \mathrm{Al}_{2} \mathrm{O}_{3} \cdot 5-6 \mathrm{H}_{2} \mathrm{O}\right)$ was extracted by elutriation of Kanuma soil from Tochigi, Japan, as previously described $[23,25,26]$.

\subsection{Sample preparation}

The sol-gel reaction system was prepared by mixing $5.0 \mathrm{~cm}^{3}$ of titanium tetraisopropoxide, 25.0 $\mathrm{cm}^{3}$ of ethanol, $0.21 \mathrm{~cm}^{3}$ of water, and $0.21 \mathrm{~cm}^{3}$ of concentrated nitric acid as the catalyst for the solgel reaction. The allophane was dispersed in the sol-gel systems of titanium tetraisopropoxide in which the $\mathrm{Al} /(\mathrm{Al}+\mathrm{Ti})$ ratios were $1 / 100$ (1.0\% allophane) and 1/1000 (0.10\% alophane). The solgel systems with and without allophane were agitated and allowed to react during ultrasonication for 1 day. The glass plates with the ITO transparent electrode were dip-coated with the sol-gel systems and then heated at $500^{\circ} \mathrm{C}$ for $30 \mathrm{~min}$ in order to prepare the titania electrodes.

The electrolyte solutions or suspensions for the photofuel cell reaction were prepared at $50^{\circ} \mathrm{C}$ by mixing $0.20 \mathrm{~mol} \mathrm{dm}^{-3}$ of an aqueous $\mathrm{NaOH}$ solution with $0,0.14,0.28,0.42$, or $0.56 \mathrm{~mol} \mathrm{dm}^{-3}$ of starch.

\subsection{Measurements}

The surface morphology of the electrode samples was observed, and their layer thickness was estimated from their cross section using a field emission scanning electron microscope (Hitachi S-4100). The particle morphology of the flakes of the electrode surface layer was observed using a transmission electron microscope (JEOL JEM-2010). The crystalline phase was determined using an X-ray diffractometer (Rigaku RINT-2200V). The specific surface areas of the flakes of the electrode samples were estimated by the BET (Brunauer-Emmett-Teller) method from the adsorption isotherms of nitrogen gas using a volumetric gas adsorption instrument (BEL Japan, BELSORP-mini). Each flake sample of $5.0 \mathrm{mg}$ was added to $50 \mathrm{~cm}^{3}$ of an $\mathrm{MB}$ aqueous solution $\left(1.0 \times 10^{-5} \mathrm{~mol} \mathrm{dm}^{-3}\right)$ and agitated in the dark for $12 \mathrm{~h}$. It was confirmed that the adsorption of MB 
was equilibrated. The amount of the MB adsorbed on each sample was estimated from the equilibrium concentration in the MB aqueous solution.

The present photofuel cells consisted of two electrodes and electrolyte as shown in Scheme 1. The electrolyte solutions were allowed to soak into the space between the electrode sample and the counter Pt electrode $(60 \mathrm{~mm} \times 25 \mathrm{~mm})$. The distance between the two electrodes was adjusted to ca. $1.0 \mathrm{~mm}$ using a spacer. The FTIR spectra of the electrolyte solution containing $0.28 \mathrm{~mol} \mathrm{dm}^{-3}$ of starch were observed as a function of the UV irradiation time using an FTIR spectrophotometer (Shimadzu IRPrestige-21) with an attenuated total reflection (ATR) accessory and a ZnSe prism in order to evaluate the changes in concentrations of the starch and the products. The UV light $(\lambda>$ $240 \mathrm{~nm}$ ) was obtained from a $150 \mathrm{~W}$ Xe short arc lamp (Ushio UXL-155). The area of the irradiated electrode was $10 \mathrm{~cm}^{2}$. The produced $\mathrm{CO}_{2}$ was dissolved as $\mathrm{CO}_{3}^{2-}$ in the present basic solutions. The concentrations of starch and $\mathrm{CO}_{3}{ }^{2-}$ estimated from the absorbance at 1003 and 1418 $\mathrm{cm}^{-1}$ of their main bands, which were calibrated using $0.20 \mathrm{~mol} \mathrm{dm}^{-3}$ of an aqueous $\mathrm{NaOH}$ solution with starch and sodium carbonate, respectively.

(Scheme 1)

Monochromatic lights obtained from a fluorescence spectrophotometer (Shimazdu RF-5300) with a $150 \mathrm{~W}$ Xe short arc lamp (Ushio UXL-155) were irradiated on the electrodes for the spectroscopic measurements. During light irradiation, the short circuit currents of the electrodes were measured in the electrolyte solutions with and without $0.28 \mathrm{~mol} \mathrm{dm}^{-3}$ of starch by a digital multimeter (ADCMT 7461A). The $I-V$ curves of the electrodes were measured in the electrolyte solutions with $0-0.56 \mathrm{~mol} \mathrm{dm}^{-3}$ of starch by a potentiostat (Hokuto Denko HSV-100) during irradiation by the $150 \mathrm{~W}$ Xe short arc lamp. The area of the irradiated electrode was $0.4 \mathrm{~cm}^{2}$. The intensity at each wavelength of the light source was obtained using a power meter (Molectron PM500A) in order to estimate the energy conversion efficiency in the electrode samples. 
The DC electrical resistance of the ITO electrode was measured using the digital multimeter (ADCMT 7461A). The resistivity values for the ITO electrodes unheated and heated at $500^{\circ} \mathrm{C}$ for $30 \mathrm{~min}$ were $2.0 \times 10^{-4}$ and $4.9 \times 10^{-4} \Omega \mathrm{cm}$, respectively. The resistivity of the heated ITO was low enough to determine the electric properties of the electrode samples.

\section{Results and discussion}

\subsection{Characterization of the electrodes}

Figure S1 shows the SEM images of the surface and cross section of the $1.0 \%$ allophane-titania composite film. This film consisted of 10-30-nm-sized particles and cannot be distinguished because the allophane particles are very small [23]. The thickness of the titania layer was ca. 400 nm. Figure S2 shows the TEM image of the $1.0 \%$ allophane-titania composite powder. The allophane consisted of ca. 5-nm-sized porous particles. In the image of the composite, the ca. 10-nm-sized particles, which exhibited lattice fringes, should indicate the titania particles. Many small amorphous particles of allophane were dispersed on the titania particle surface. The allophane particles were tightly connected to the titania surface.

Figure S3 shows the XRD patterns of the titania and allophane-titania composite films. The peaks at $25.3^{\circ}, 37.8^{\circ}$, and $48.1^{\circ}$ assigned to anatase-type crystals were observed in all the films. Their crystallite sizes were estimated using Sherrer's equation to be $19 \mathrm{~nm}$ for the titania, $17 \mathrm{~nm}$ for the $0.10 \%$ allophane-titania composite, and $14 \mathrm{~nm}$ for the $1.0 \%$ allophane-titania composite. The sizes were smaller for the allophane-containing films than for the only titania film. This result indicates that the allophane particles prevented the crystal growth of the titania because they were highly dispersed in the entire film and strongly bonded to the titanium alkoxide polymers and the titania gel particles [23]. The dispersion of allophane particles influenced the particle growth and 
crystallization process of titania. The surface morphology and the crystal properties of the electrode samples were already shown in the previous study [24].

Table 1 shows the specific surface area and the MB adsorption amount for the flakes of the electrode samples. The specific surface area of the allophane was ca. 4 times higher than that of the titania. The allophane surface should be more hydrophobic than the titania surface. Therefore, allophane adsorbed a much greater amount of MB than the titania. The addition of $1.0 \%$ allophane to the titania increased its adsorption ability by ca. $10 \%$ due to the improvement of the effective surface area.

\section{(Table 1)}

\subsection{Photocatalytic reaction on the electrodes}

The photocatalytic degradation of starch and the resulting $\mathrm{CO}_{2}$ production were observed on the titania electrode using the electrolyte solution with starch during the UV irradiation by FTIR measurements. The $\mathrm{CO}_{2}$ was dissolved as $\mathrm{CO}_{3}{ }^{2-}$ in the present basic solutions. Figure 1 shows the changes in the FTIR spectrum of the starch solution during the photocatalytic degradation using the titania electrode. Figure 2 shows the time course of the concentrations of starch and $\mathrm{CO}_{3}{ }^{2-}$ estimated from the absorbance at 1003 and $1418 \mathrm{~cm}^{-1}$, respectively, during the photocatalytic degradation using all the electrodes. The starch concentration decreased with an increase in the UV irradiation time. The decrease in the starch concentration by adsorption onto the electrodes can be negligible because the film thickness was ca. $400 \mathrm{~nm}$ and the total surface area of the films was very small.

(Figures 1 and 2)

The degradation rate was fast in the order of using the $0.10 \%$ allophane-titania composite, $1.0 \%$ allophane-titania composite, and titania electrodes, indicating their photocatalytic activity. The allophane particles can adsorb starch and the partial oxidation products and donate them to the titania. The photocatalytic activity was enhanced by adding a small amount of allophane due to the effective 
adsorption and degradation relay [23,24]. However, a larger amount of allophane decreased the degradation rate due to depressing the photocatalytic function of the titania. The effect of adding allophane, on the starch degradation behavior, corresponded to the glucose degradation observed in the previous study.

The concentration of $\mathrm{CO}_{3}{ }^{2-}$ also increased with an increase in the UV irradiation time in the same rate order as the starch degradation rate. The $0.10 \%$ allophane-titania composite electrode exhibited the highest performance of the three electrodes. This result indicated that the starch was oxidized during the photocatalytic reaction process. Six times the amount of $\mathrm{CO}_{2}$ than that of starch should be produced from the oxidation of starch. Strictly, the change in the $\mathrm{CO}_{3}{ }^{2-}$ concentration was smaller by ca. $50 \%$ than the amount expected from the decrease in the starch concentration. The partial oxidative products of starch, such as carboxyl, carbonyl, and alcoholic compounds, should be easily adsorbed on the titania surface [25-30]. Therefore, they were not detected in the water phase. It was difficult to determine such organic compounds on the electrode surface due to their very small amounts.

Hydroxyl ions are oxidized by holes and form hydroxyl radicals on the titania under basic conditions. The starch $\left(\left(\mathrm{C}_{6} \mathrm{H}_{10} \mathrm{O}_{5}\right)_{\mathrm{n}}\right)$ molecules should be oxidized by the hydroxyl radicals on the titania and produce $\mathrm{CO}_{2}$ and $\mathrm{H}_{2} \mathrm{O}$. $\mathrm{H}_{2} \mathrm{O}$ should be reduced with oxygen by the electrons on the counter electrodes. Adopting the glucose degradation process [24], the ideal reactions can be expressed as follows:

Titania electrode:

$$
\begin{aligned}
& 4 \mathrm{OH}^{-}+4 \mathrm{~h}^{+} \rightarrow 4 \mathrm{OH} \cdot \\
& 1 / 6\left(\mathrm{C}_{6} \mathrm{H}_{10} \mathrm{O}_{5}\right)_{\mathrm{n}}+4 \mathrm{nOH} \cdot \rightarrow \mathrm{nCO}_{2}+17 / 6 \mathrm{nH}_{2} \mathrm{O}
\end{aligned}
$$

Counter electrode:

$$
2 \mathrm{H}_{2} \mathrm{O}+\mathrm{O}_{2}+4 \mathrm{e}^{-} \rightarrow 4 \mathrm{OH}^{-}
$$


Actually, the starch molecules were partially oxidized judging from the small amount of $\mathrm{CO}_{2}$ produced. The reaction rate became slower with the elapse of time because the oxygen concentration in the solution was very low.

\subsection{Photofuel cell properties of the electrodes}

Figure 3 shows the photocurrent spectra of the electrodes observed using the electrolyte solutions with and without starch during UV irradiation. The shape of all the spectra was similar to the absorption spectra of titania exhibiting the absorption edge at around $400 \mathrm{~nm}$. This indicated that the photocurrent was generated by the excited electrons in the titania [31,32]. Figure 4 shows the $I-$ $V$ curves of the electrode observed under the same conditions. The photoelectric conversion properties under each condition were summarized in Table S1. The photocurrent due to water splitting was observed using a starch-free electrolyte solution. The short circuit current values decreased with an increase in the amount of allophane in the titania electrode using a starch-free electrolyte solution. This result indicated that allophane decreased the electronic conductivity in the electrode, affecting the photoelectric conversion efficiency, even though the photocatalytic activity for starch degradation was best enhanced by adding $0.10 \%$ allophane. It is difficult to estimate the fuel-electric energy conversion efficiency in the present study because the conditions of the starch degradation and $I-V$ measurement were different. The photoelectric conversion efficiency was very low because the titania layer was very thin, ca. $400 \mathrm{~nm}$ [24]. However, the efficiency values for the electrodes corresponded to their photocatalytic activity.

(Figure 3)

The short circuit current values observed using the starch-containing electrolyte solution were significantly higher than those observed using the starch-free solution. This indicated that the oxidation of the starch enhanced the generation of electricity. The highest photofuel cell performance was observed using the $0.10 \%$ allophane-containing titania electrode because the allophane increased the starch concentrations on the electrode surface without decreasing its 
electronic conductivity. The higher amount of allophane decreased the photocurrent due to decreasing the electronic conductivity. Allophane particles should be highly dispersed in the titania in order to effectively function as an adsorbent and prevent their aggregation causing action as an insulator. The photocatalytic reaction was promoted by adding a small amount of allophane due to the effective adsorption and degradation relay, which promoted the consumption of holes and suppressed the electron-hole recombination.

(Figure 4)

The photocurrent values were close to those of glucose observed in the previous study [24]. The polymer molecules were also adsorbed on the active sites and effectively degraded by the photocatalytic reaction. The thinness and porous structure of the films in the present electrodes decreased their parallel resistance and the open circuit voltage even though the theoretical value is ca. 1.2 V. The present values corresponded to those obtained in our previous study $[10,11,24]$.

The photofuel cells require the generation of electricity using a highly concentrated solution or suspension of the fuel materials. Figure 5 shows the dependence of the starch concentration on the $I-V$ curves of the allophane--titania composite electrode observed during the UV irradiation. The photoelectric conversion properties under each condition were also shown in Table S2. The systems containing a concentration higher than $0.28 \mathrm{~mol} \mathrm{dm}^{-3}$ of starch were opaque. The short circuit current value and photoelectric conversion efficiency increased with an increase in the starch. The starch molecules adsorbed from even the suspension on the electrode can be used for the generation of electricity. The adsorption amount should be saturated in the suspension containing a concentration higher than $0.56 \mathrm{~mol} \mathrm{dm}{ }^{-3}$ of starch. The $I-V$ curves were obtained in the starch-free electrolyte using the electrodes on which starch was adsorbed from the starch solutions and shown in Figure 6. The photoelectric conversion properties of these electrodes were also shown in Table S3. Higher short circuit photocurrent and photoelectric conversion efficiency were observed in the electrode on which starch was adsorbed from a higher concentration of the starch solution or 
suspension although the adsorption amount of starch was too low to detect. Such a phenomenon was not observed using the titania electrode. Allophane increased the capacity of the electrode to adsorb the starch molecules. This brought the molecules close to the titania nanoparticles.

(Figures 5 and 6)

\section{Conclusions}

Allophane-titania nanocomposite electrodes for photofuel cells were prepared from titanium alkoxide sols dispersing the natural clay mineral allophane. Starch was used as a fuel material in order to examine the degradation reaction, in its solution and suspension, as the pre-stage using cellulose compounds. We investigated the photocatalytic oxidative degradation of the starch solutions and suspensions in the photofuel cells using allophane-titania nanocomposite electrodes and their energy conversion properties. The effect of the adsorption ability of allophane on the photofuel cell reactions was also examined. Electrochemical measurements indicated that the oxidative degradation of starch in the solutions and suspensions enhanced the generation of electricity during UV irradiation. $\mathrm{CO}_{2}$ was observed as the degradation product. The highest photofuel cell performance was observed using the $0.10 \%$ allophane-containing titania electrode because the allophane increased the starch concentrations on the electrode surface without decreasing its electronic conductivity. Allophane particles should be highly dispersed in the titania in order to effectively function as an adsorbent and prevent their aggregation causing action as an insulator. A higher short circuit photocurrent was observed in the electrode on which starch was adsorbed from a higher concentration of starch solution. Allophane effectively adsorbed the starch molecules and then brought them close to the titania nanoparticles, on which their oxidation induced the electrogeneration. 


\section{Acknowledgement}

This work was supported by JSPS KAKENHI Grant Number 24550153.

\section{References}

[1] B. O’Regan, M. Grätzel, Nature 353 (1991) 737-740.

[2] M. K. Nazeeruddin, A. Kay, I. Rodicio, R. Hamphry-Baker, E. Müeller, P. Liska, N. Vlachopoulos, M. Grätzel, J. Am. Chem. Soc. 115 (1993) 6382-6390.

[3] M. Grätzel, J. Photochem. Photobiol. C: Photochem. Rev. 4 (2003) 145-153.

[4] M. Kaneko, J. Nemoto, H. Ueno, N. Gokan, K. Ohnuki, M. Horikawa, R. Saito, T. Shibata, Electrochem. Commun. 8 (2006) 336-340.

[5] H. Ueno, J. Nemoto, K. Ohnuki, M. Horikawa, M. Hoshino, M. Kaneko, J. Appl. Electrochem. 39 (2009) 1897-1905.

[6] M. Antoniadou, P. Lianos, Catal. Today 114 (2009) 166-171.

[7] M. Antoniadou, D. I. Kondarides, P. Lianos, Catal. Lett. 129 (2009) 344-349.

[8] M. Antoniadou, P. Lianos, Appl. Catal. B: Environ. 99 (2010) 307-313.

[9] M. Antoniadou, D. I. Kondarides, D. Labou, S. Neophytides, P. Lianos, Solar Energy Mater. Solar Cells 9 (2010) 592-597.

[10] H. Nishikiori, K. Isomura, Y. Uesugi, T. Fujii, Appl. Catal. B: Environ. 106 (2011) 250-254.

[11] H. Nishikiori, Y. Kato, T. Fujii, Res. Chem. Intermed. 38 (2012) 241-250.

[12] Y. Kitagawa, Am. Mineralogist 56 (1971) 465-475. 
[13] T. Henmi, K. Wada, Am. Mineralogist 61 (1976) 379-390.

[14] S. Wada, K. Wada, Clay Miner. 12 (1977) 289-298.

[15] S. J. van der Gaast, K. Wada, S. -I. Wada, Y. Kakuto, Clays Clay Miner. 33 (1985) 237-243.

[16] P. L. Hall, G. J. Churkman, B. K. G. Theng, Clays Clay Miner. 33 (1985) 345-349.

[17] E. Hanudin, N. Matsue, T. Henmi, Clay Sci. 11 (1999) 57-72.

[18] H. Yoneyama, S. Haga, S. Yamanaka, J. Phys. Chem. 93 (1989) 4833-4837.

[19] Y. Kitayama, T. Kodama, M. Abe, H. Shimotsuma, J. Porous Mater. 5 (1998) 121-126.

[20] T. Tao, J. J. Yang, G. E. Maciel, Environ. Sci. Technol. 33 (1999) 74-80.

[21] S. Suárez, J. M. Coronado, R. Portela, J. C. Martín, M. Yates, P. Avila, B. Sánchez, Environ. Sci. Technol. 42 (2008) 5892-5896.

[22] T. L. R. Hewer, S. Suárez, J. M. Coronado, R. Portela, P. Avila, B. Sanchez, Catal. Today 143 (2009) 302-308.

[23] H. Nishikiori, M. Furukawa, T. Fujii, Appl. Catal. B: Environ. 102 (2011) 470-474.

[24] H. Nishikiori, M. Ito, R. A. Setiawan, A. Kikuchi, T. Yamakami, T. Fujii, Chem. Lett. 41 (2012) $725-727$.

[25] H. Nishikiori, J. Shindoh, N. Takahashi, T. Takagi, N. Tanaka, T. Fujii, Appl. Clay Sci. 43 (2009) 160-163.

[26] H. Nishikiori, K. Kobayashi, S. Kubota, N. Tanaka, T. Fujii, Appl. Clay Sci. 47 (2010) $325-329$. 
[27] O. Klug, W. Forsling, Langmuir 15 (1999) 6961-6968.

[28] J. Rosenqvist, K. Axe, S. Sjöberg, P. Persson, Colloids Surf. A: Physicochem. Eng. Asp. 220 (2003) 91-104.

[29] J. M. Guil, N. Homs, J. Llorca, P. R. de la Piscina, J. Phys. Chem. B 109 (2005) 10813-10819.

[30] Y. J. Lee, R. J. Reeder, Geochim. Cosmochim. Acta 70 (2006) 2253-2263.

[31] H. Nishikiori, Y. Uesugi, S. Takami, R. A. Setiawan, T. Fujii, W. Qian, M. A. El-Sayed, J. Phys. Chem. C 115 (2011) 2880-2887.

[32] H. Nishikiori, Y. Uesugi, R. A. Setiawan, T. Fujii, W. Qian, M. A. El-Sayed, J. Phys. Chem. C 116 (2012) 4848-4854. 
Table 1 Specific surface area and MB adsorption amount of the flakes of the electrode samples.

\begin{tabular}{ccc}
\hline Sample & Specific surface $\mathbf{a r e a} / \mathbf{~ m}^{\mathbf{2}} \mathbf{g}^{\mathbf{- 1}}$ & MB adsorption amount $/ \boldsymbol{\mu m o l ~ \mathbf { ~ g } ^ { \mathbf { 1 } }}$ \\
\hline Titania & $84 \pm 4$ & $13.1 \pm 0.5$ \\
$0.1 \%$ allophane-titania & $84 \pm 8$ & $13.3 \pm 0.7$ \\
$1.0 \%$ allophane-titania & $88 \pm 5$ & $14.5 \pm 0.8$ \\
Allophane & $310 \pm 20$ & $240 \pm 20$ \\
\hline
\end{tabular}




\section{Figure captions}

Scheme 1 Structure of the photofuel cell.

Figure 1 Changes in the FTIR spectra of the electrolyte solution containing $0.28 \mathrm{~mol} \mathrm{dm}^{-3}$ of starch during photocatalytic degradation using the titania electrode.

Figure 2 Changes in the concentrations of (a) starch and (b) $\mathrm{CO}_{2}$ during photocatalytic degradation using the (1) titania electrode and the allophane-titania composite electrodes containing (2) $0.10 \%$ and (3) $1.0 \%$ allophane.

Figure 3 Photocurrent spectra of the (1) titania electrode and the allophane-titania composite electrodes containing (2) $0.10 \%$ and (3) $1.0 \%$ allophane observed using the electrolyte solutions with and without $0.28 \mathrm{~mol} \mathrm{dm}^{-3}$ of starch during the UV irradiation.

Figure $4 I-V$ curves of the (1) titania electrode and the allophane-titania composite electrodes containing (2) $0.10 \%$ and (3) $1.0 \%$ allophane observed using the electrolyte solutions with and without $0.28 \mathrm{~mol} \mathrm{dm}^{-3}$ of starch during the UV irradiation. 
Figure $5 I-V$ curves of the allophane-titania composite electrode containing $0.10 \%$ allophane observed using the electrolyte solutions or suspensions with starch during the UV irradiation, in which the concentrations of starch were (1) 0 , (2) 0.14 , (3) 0.28 , (4) 0.42 , and (5) $0.56 \mathrm{~mol} \mathrm{dm}^{-3}$.

Figure $6 I-V$ curves of the allophane-titania composite electrode containing $1.0 \%$ allophane on which starch was adsorbed from (1) 0.14 , (2) 0.28 , (3) 0.42 , and (4) $0.56 \mathrm{~mol} \mathrm{dm}^{-3}$ of starch solutions or suspensions observed during the UV irradiation. 
Scheme 1

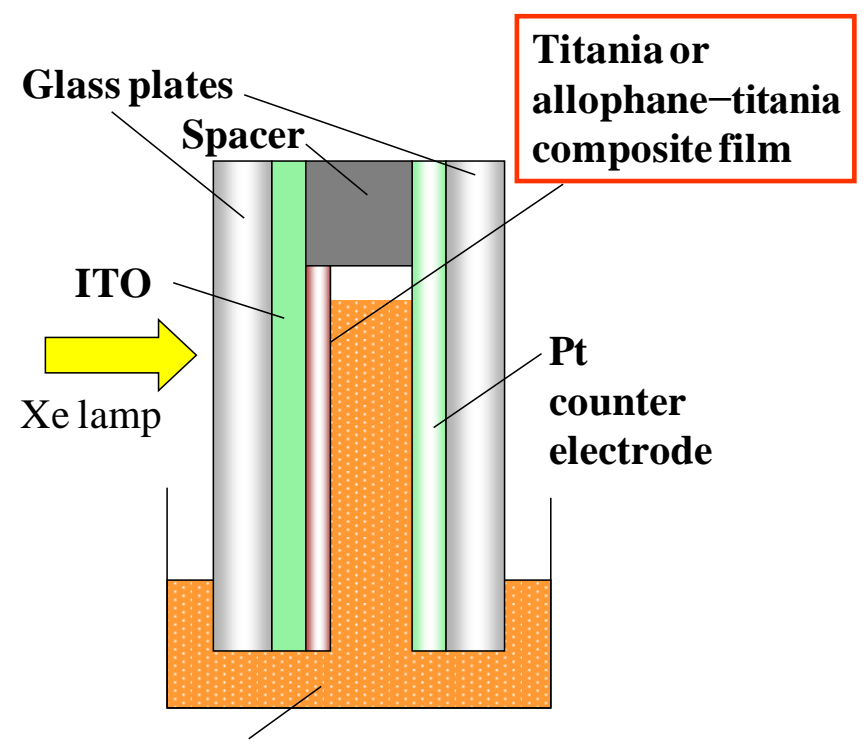

Electrolyte with or without starch 
Figure 1

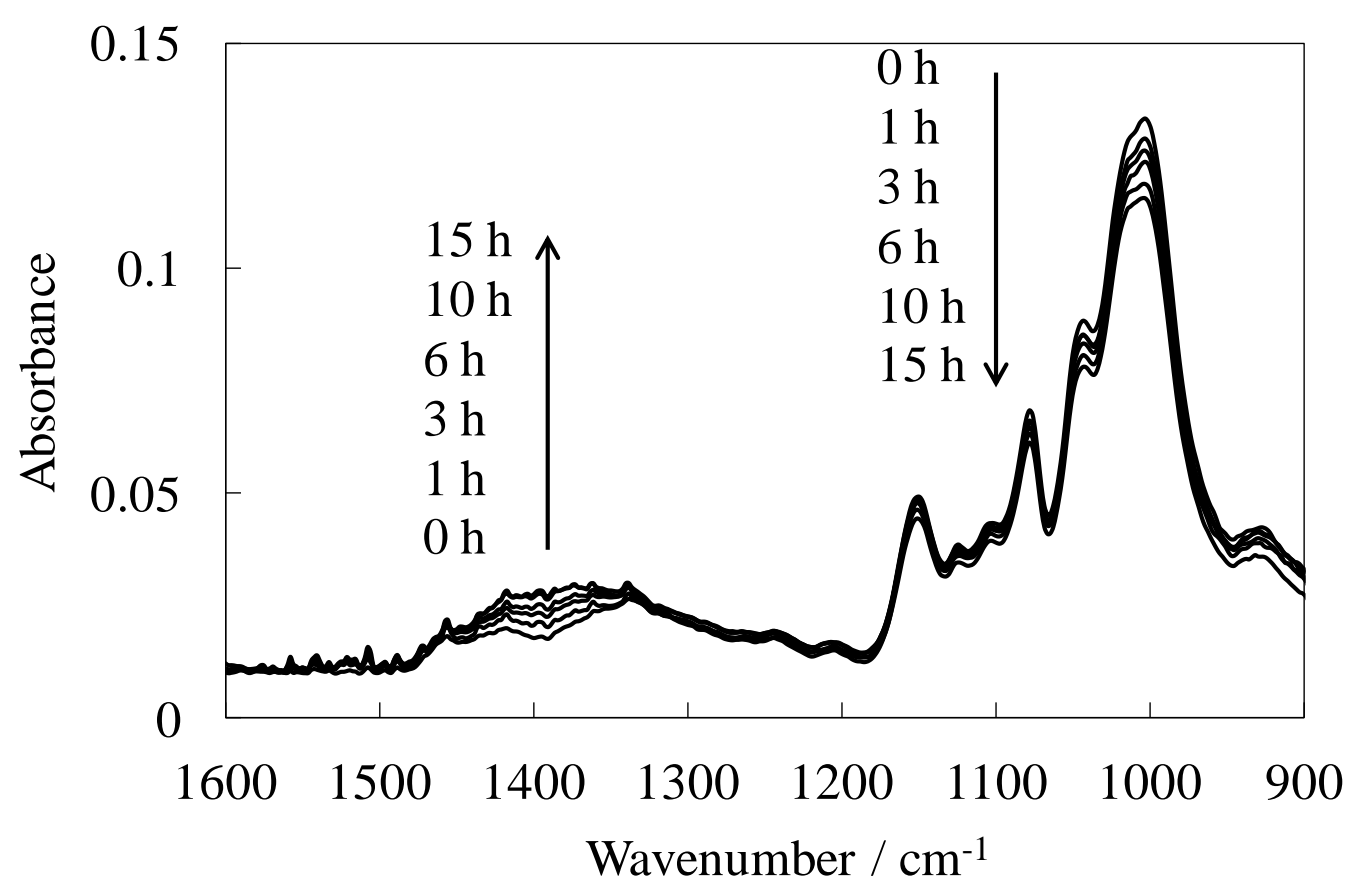


Figure 2
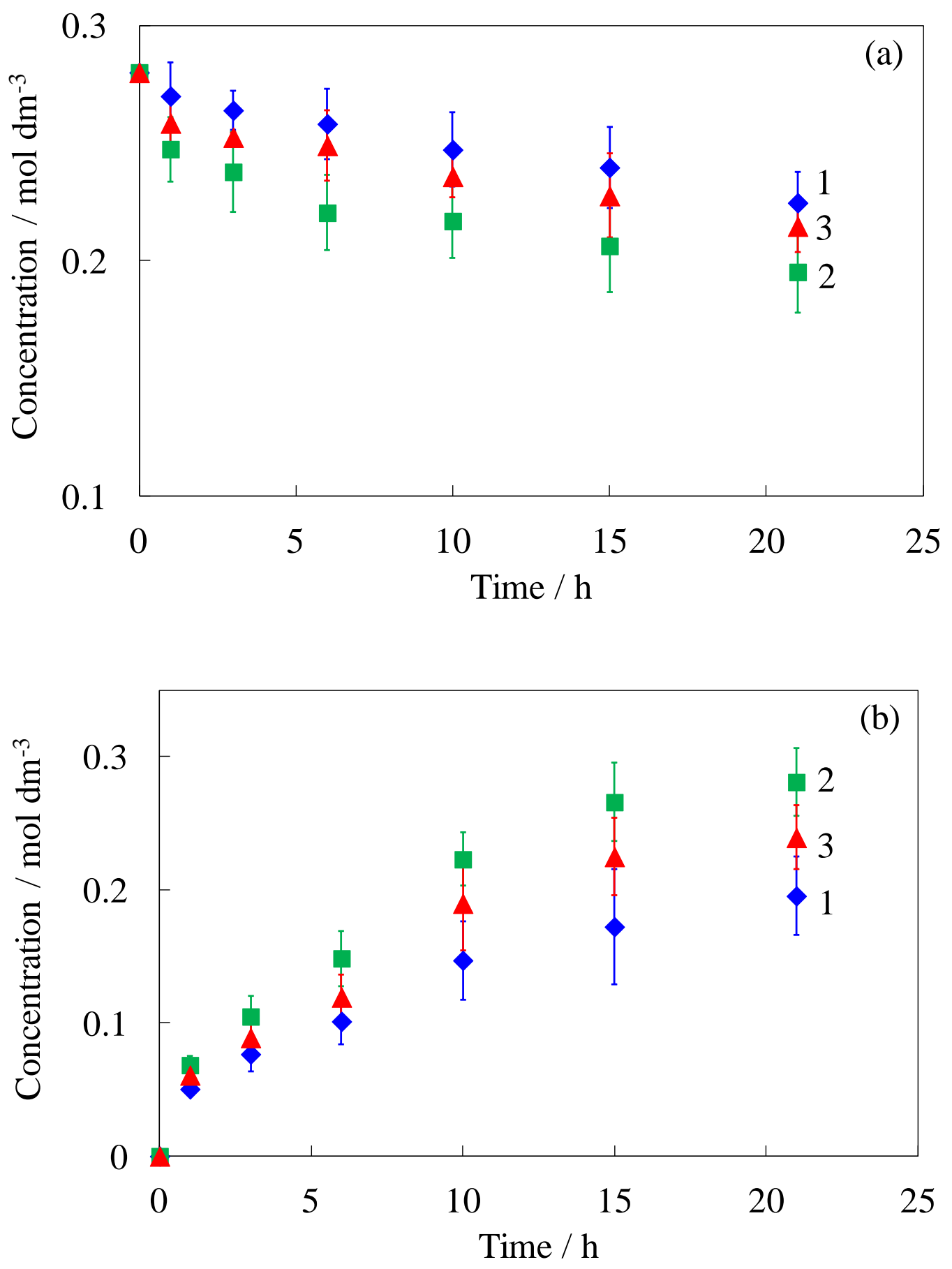
Figure 3

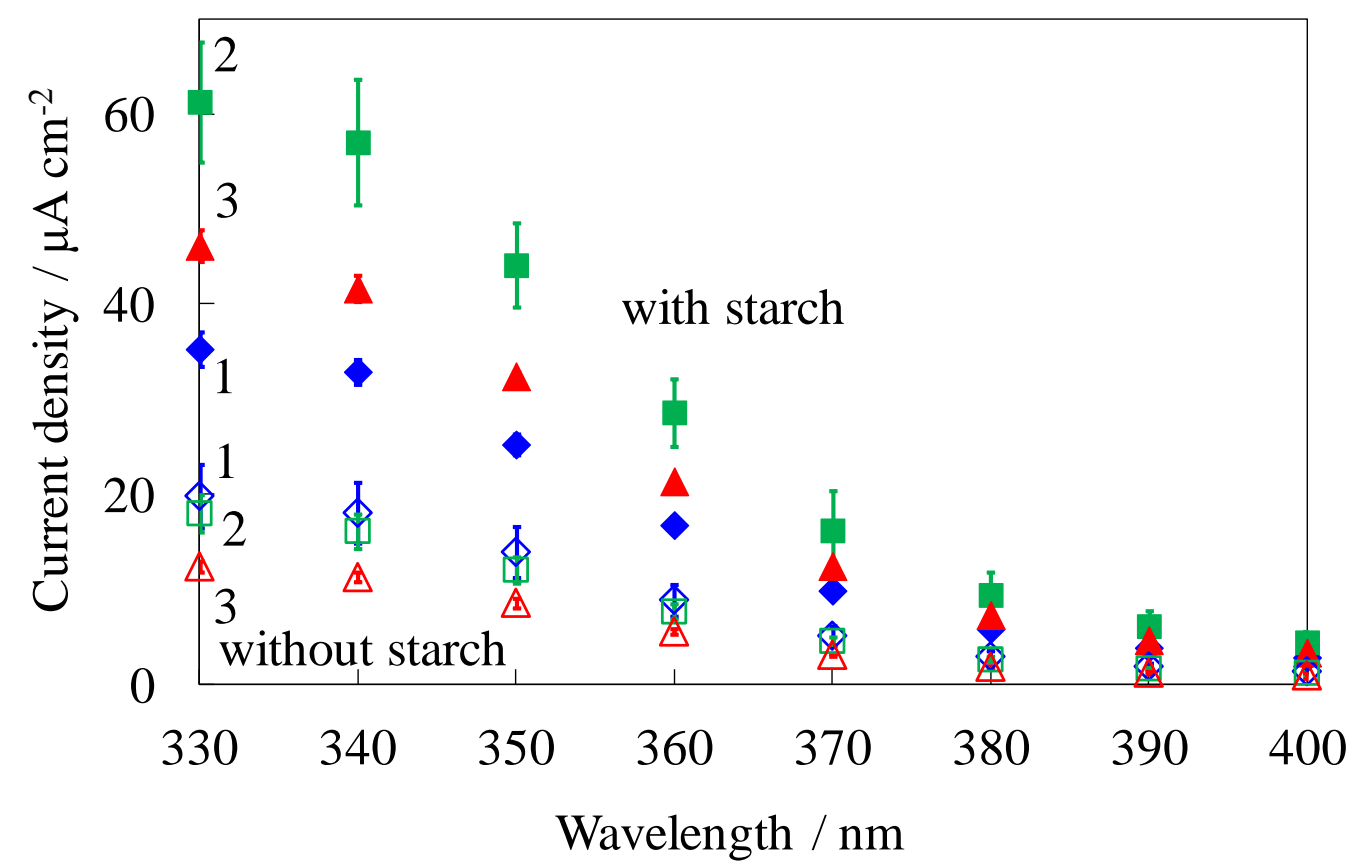


Figure 4

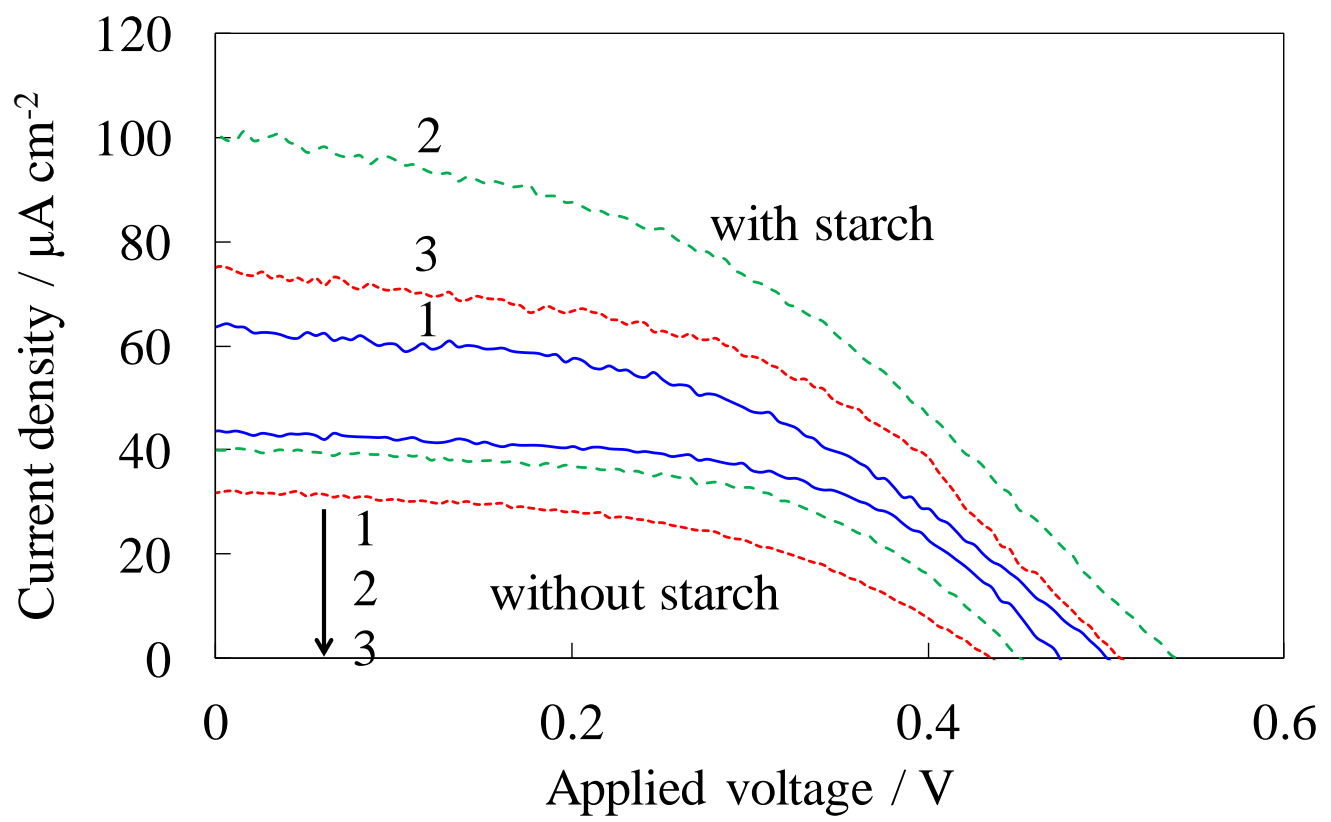


Figure 5

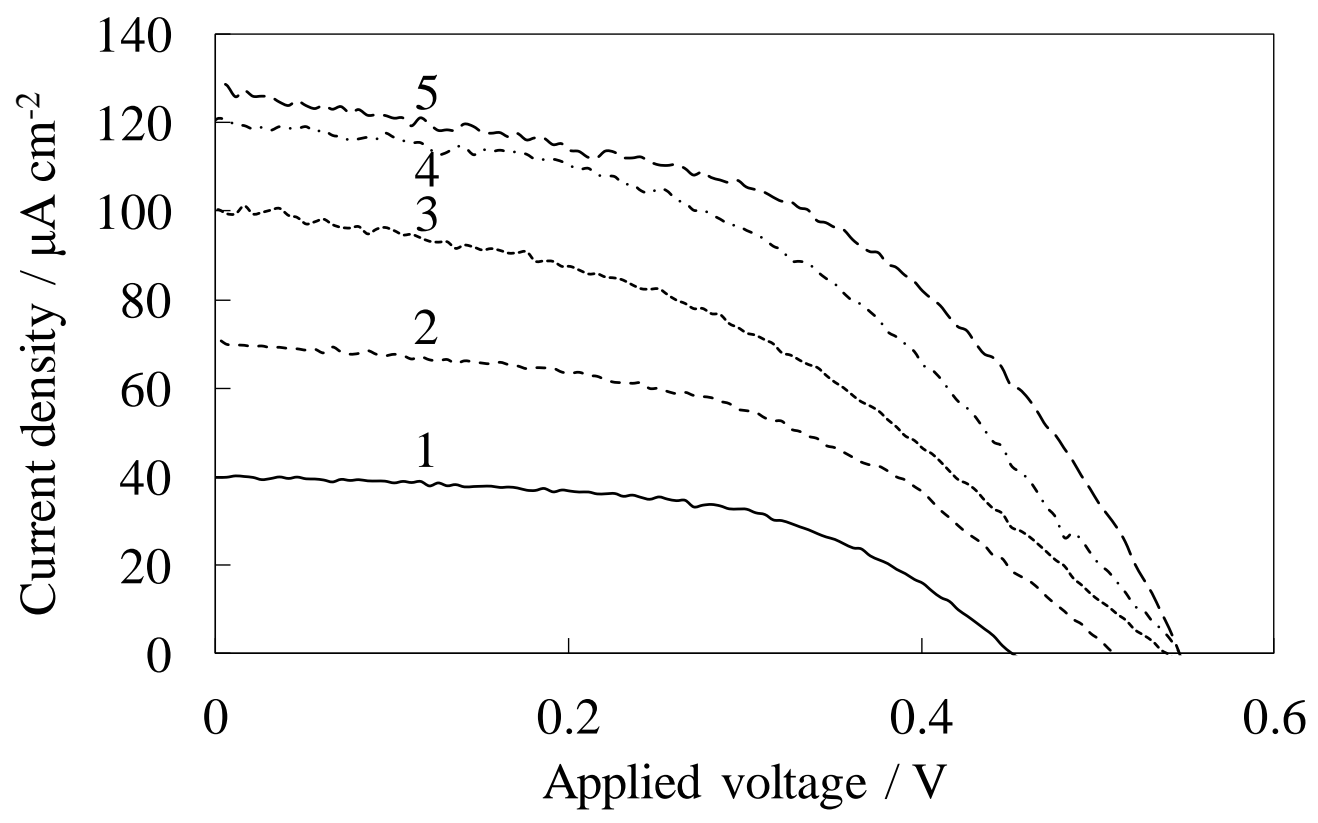


Figure 6

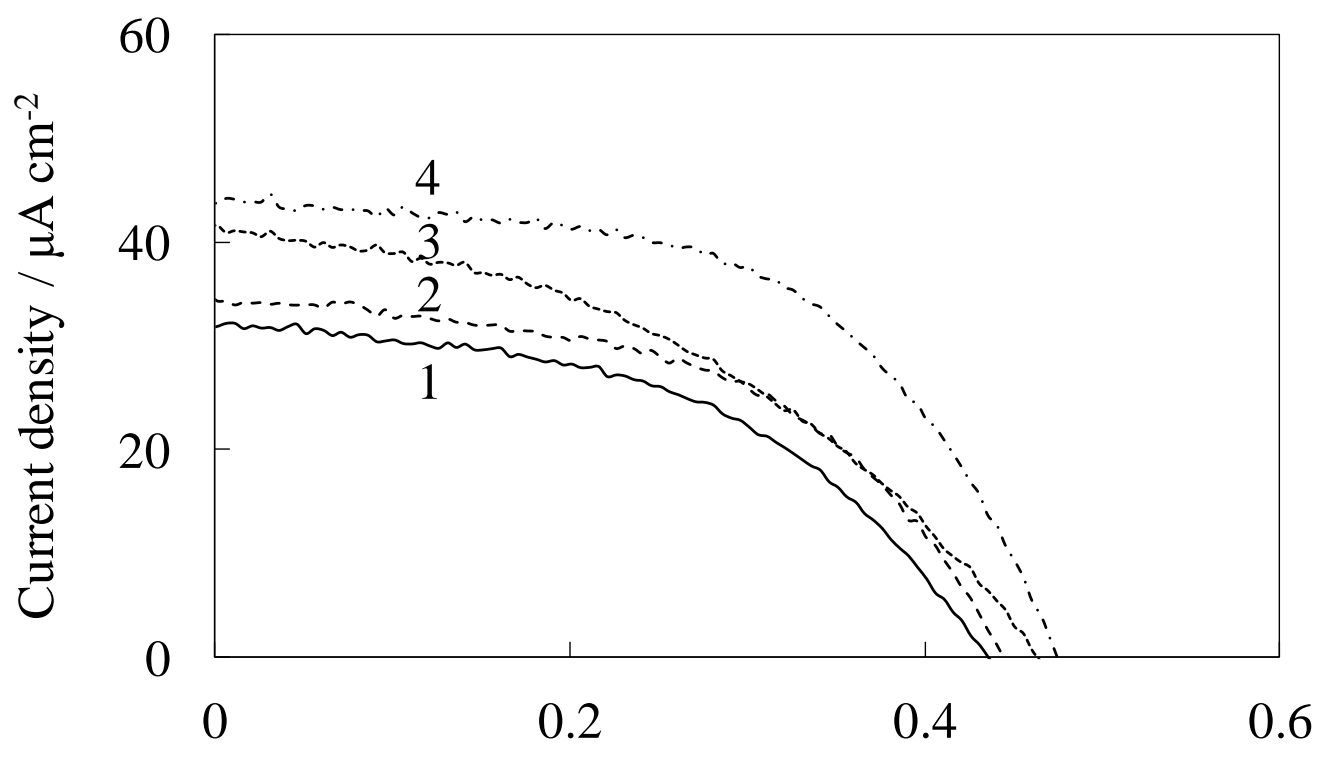

Applied voltage / V 


\section{Supplementary Information}

Figure S1 SEM images of the (a) surface and (b) cross section of the $1.0 \%$ allophane-titania composite film.

Figure S2 TEM image of the the $1.0 \%$ allophane-titania composite powder.

Figure S3 XRD patterns of the (1) titania film and the allophane-titania composite films containing (2) $0.10 \%$ and (3) $1.0 \%$ allophane. 
Figure S1

(a)

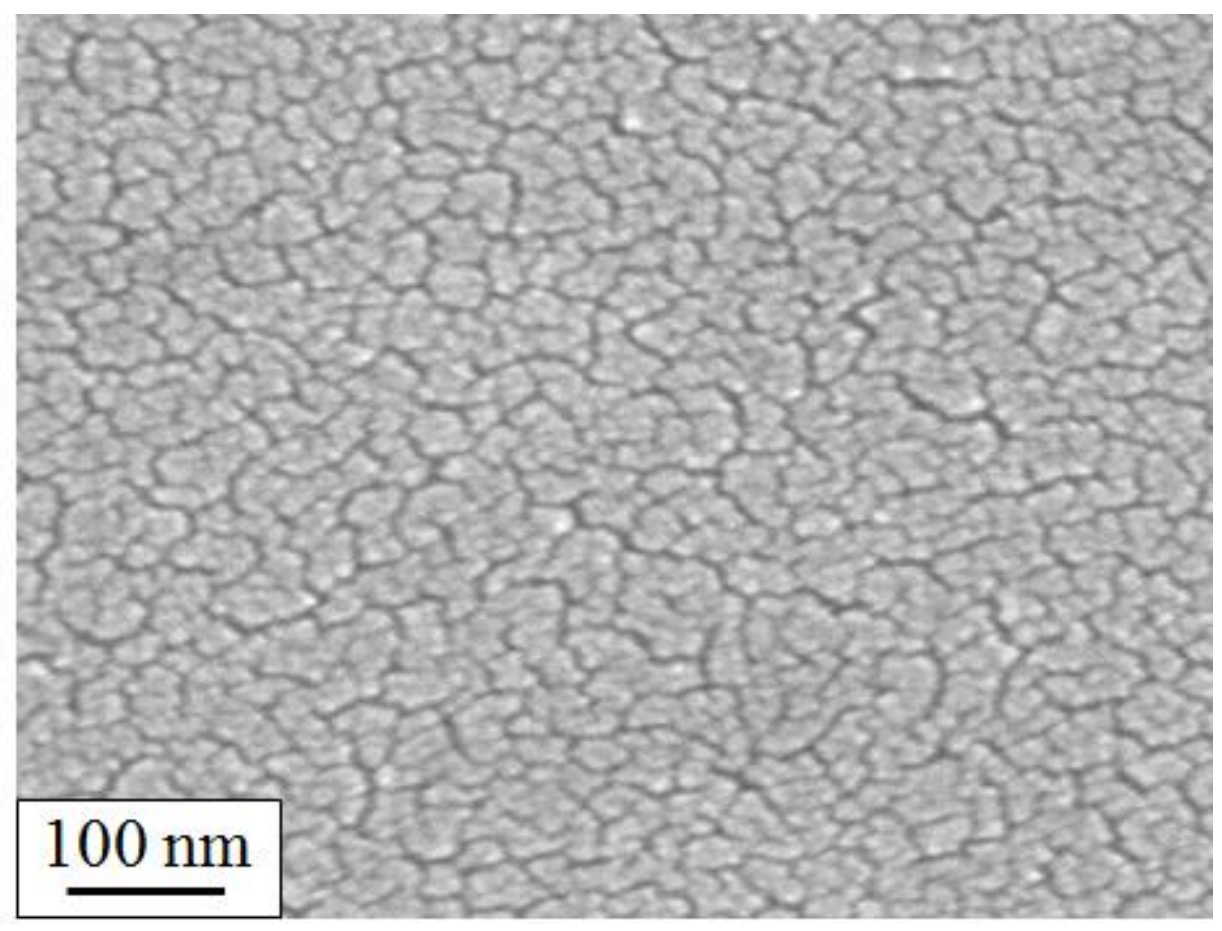

(b)

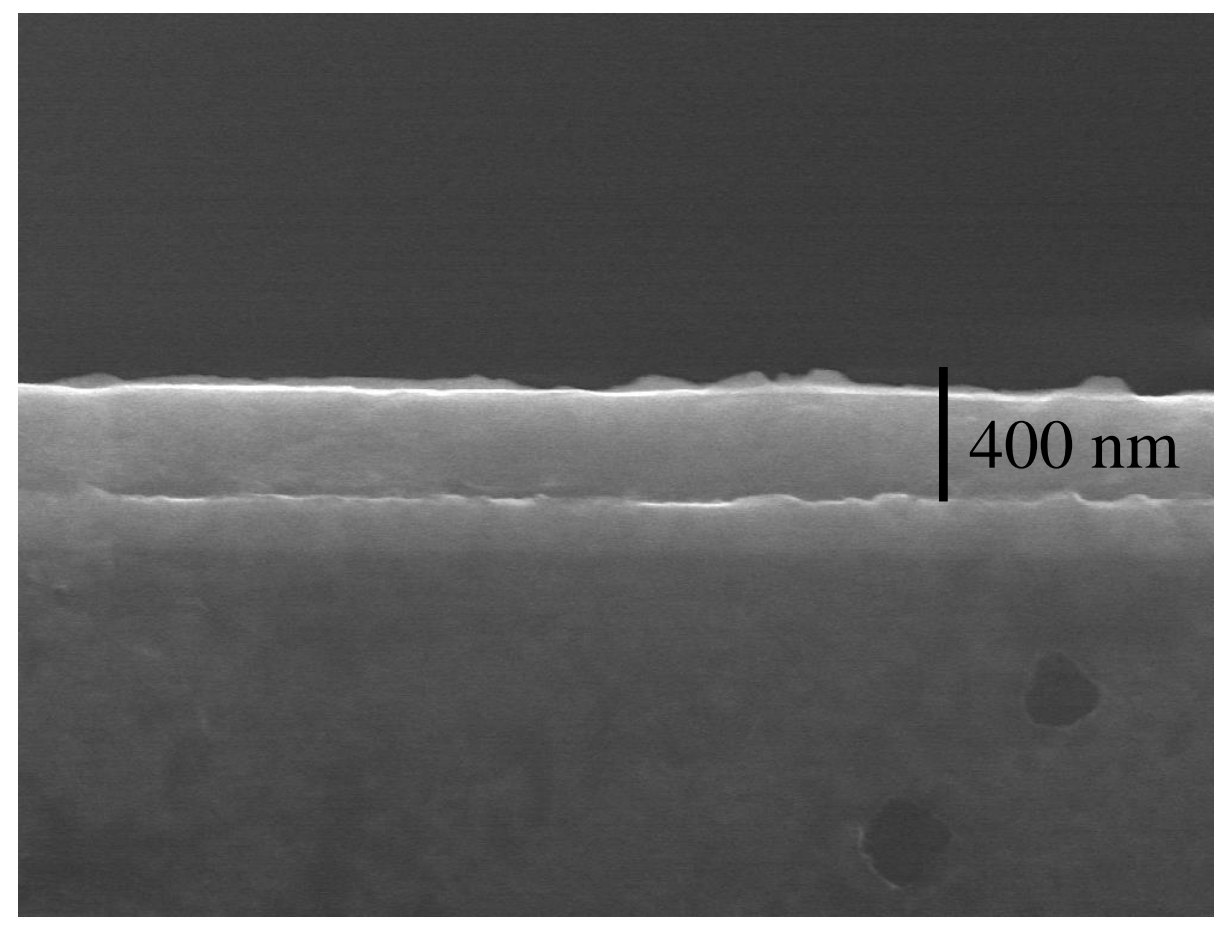


Figure S2

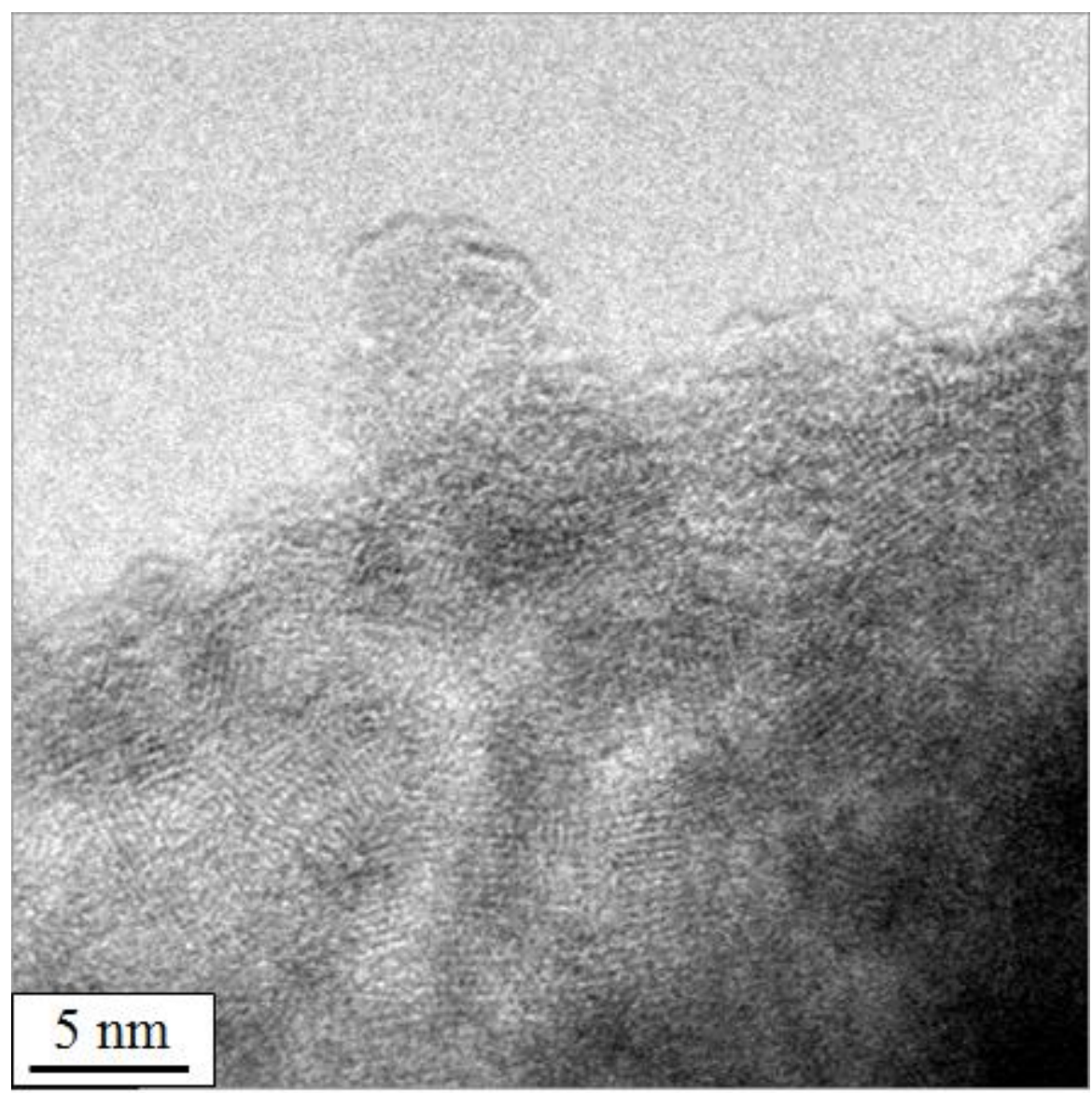


Figure S3

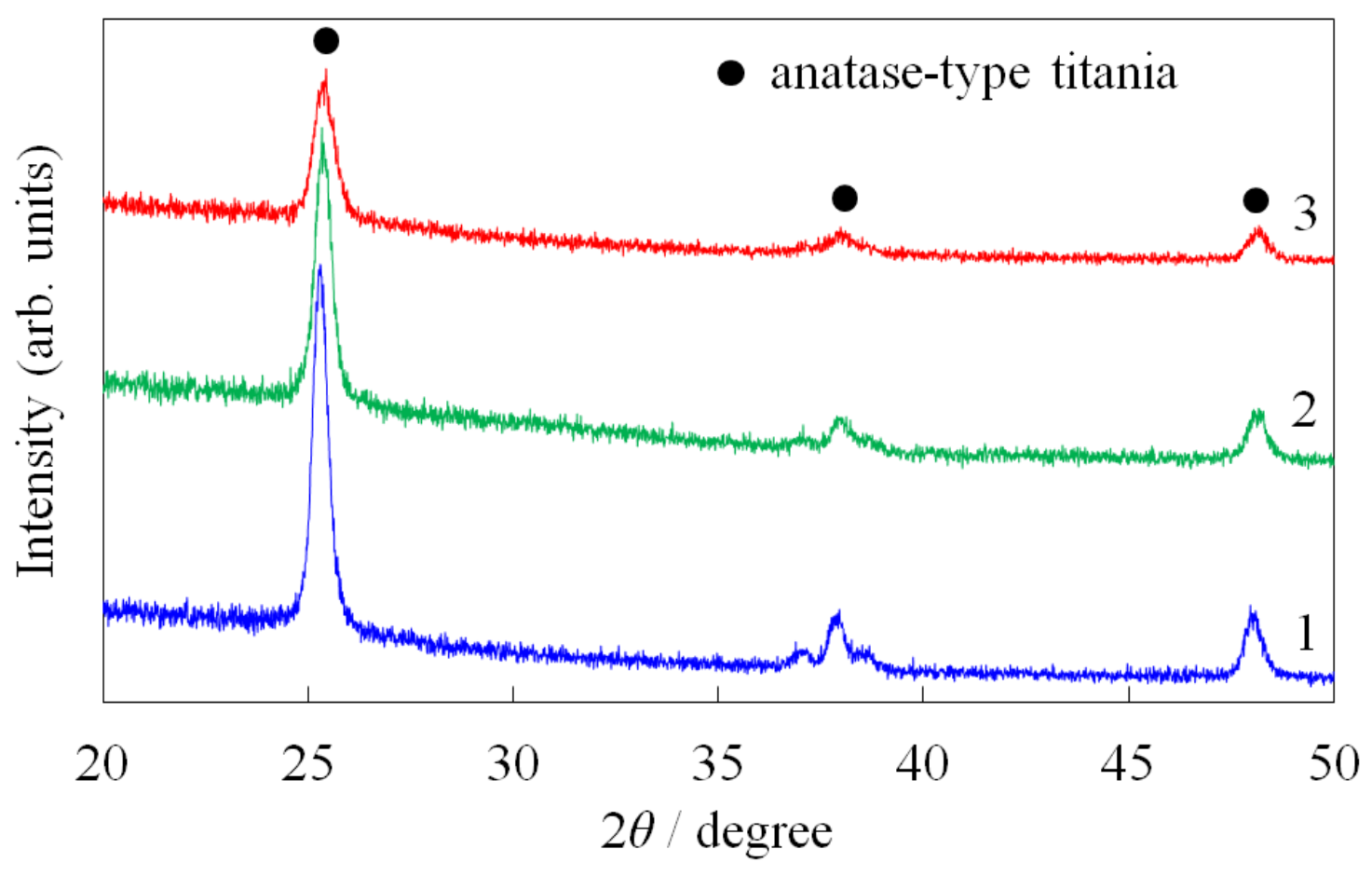


Table S1 Photoelectric conversion properties of the titania electrode and the allophane-titania composite electrodes observed using the electrolyte solutions with and without starch during the UV irradiation.

\begin{tabular}{cccccc}
\hline Sample & $\boldsymbol{I S C}_{\mathbf{S C}} / \mathbf{m A ~ \mathbf { ~ m } ^ { - 2 }}$ & $\boldsymbol{V}_{\mathbf{O C}} / \mathbf{V}$ & $\boldsymbol{F F}$ & $\boldsymbol{P}_{\mathbf{m a x}} / \boldsymbol{\mu W} \mathbf{~ c m}^{-\mathbf{2}}$ & $\boldsymbol{\eta} / \boldsymbol{\%}$ \\
\hline Without starch & & & & & \\
$\quad$ Titania & 43.6 & 0.476 & 0.541 & 11.2 & 0.0562 \\
0.1\% allophane-titania & 39.9 & 0.451 & 0.547 & 9.84 & 0.0492 \\
1.0\% allophane-titania & 31.9 & 0.436 & 0.491 & 6.84 & 0.0342 \\
$\quad$ With starch & & & & & \\
$\quad$ Titania & 63.8 & 0.501 & 0.460 & 14.7 & 0.0736 \\
0.1\% allophane-titania & 100 & 0.541 & 0.407 & 22.1 & 0.111 \\
$1.0 \%$ allophane-titania & 75.2 & 0.506 & 0.466 & 17.7 & 0.0887 \\
\hline
\end{tabular}

$I_{\mathrm{SC}}:$ short circuit photocurrent density; $V_{\mathrm{OC}}:$ open circuit voltage; $F F$ : fill factor; $P_{\max }:$ maximum power; $\eta$ : photoelectric conversion efficiency under $20 \mathrm{~mW} \mathrm{~cm} \mathrm{~cm}^{-2} \mathrm{UV}$ light source.

Table S2 Photoelectric conversion properties of the allophane-titania composite electrode containing $0.10 \%$ allophane observed using the electrolyte solutions or suspensions with each concentration of starch during the UV irradiation.

\begin{tabular}{cccccc}
\hline Starch concentration $/ \mathbf{m o l ~ d m}^{-3}$ & $\boldsymbol{I}_{\mathbf{S C}} / \mathbf{~} \mathbf{~ A ~ \mathbf { ~ c m } ^ { - 2 }}$ & $\boldsymbol{V}_{\mathbf{O C}} / \mathbf{V}$ & $\boldsymbol{F F}$ & $\boldsymbol{P}_{\max } / \boldsymbol{\mu W} \mathbf{~ c m}^{-\mathbf{2}}$ & $\boldsymbol{\eta} / \boldsymbol{\%}$ \\
\hline 0 & 39.9 & 0.451 & 0.547 & 9.84 & 0.0492 \\
0.14 & 71.0 & 0.506 & 0.468 & 16.8 & 0.0841 \\
0.28 & 100 & 0.541 & 0.407 & 22.1 & 0.111 \\
0.42 & 121 & 0.551 & 0.444 & 29.6 & 0.148 \\
0.56 & 129 & 0.546 & 0.485 & 34.1 & 0.171 \\
\hline
\end{tabular}

$I_{\mathrm{SC}}:$ short circuit photocurrent density; $V_{\mathrm{OC}}:$ open circuit voltage; $F F$ : fill factor; $P_{\max }:$ maximum power. $\eta$ : photoelectric conversion efficiency under $20 \mathrm{~mW} \mathrm{~cm} \mathrm{cV}^{-2} \mathrm{UV}$ light source. 
Table S3. Photoelectric conversion properties of the allophane-titania composite electrode containing $1.0 \%$ allophane on which starch was adsorbed from each concentration of starch solution or suspension observed during the UV irradiation.

\begin{tabular}{|c|c|c|c|c|c|}
\hline Starch concentration $/ \mathrm{mol} \mathrm{dm}^{-3}$ & $I_{\mathrm{SC}} / \mathbf{m A ~ \mathbf { c m } ^ { - 2 }}$ & $V_{\mathrm{OC}} / \mathbf{V}$ & $F F$ & $P_{\max } / \mu \mathrm{W} \mathbf{c m}^{-2}$ & $\eta / \%$ \\
\hline 0.14 & 32.2 & 0.441 & 0.492 & 6.99 & 0.0349 \\
\hline 0.28 & 34.3 & 0.441 & 0.522 & 7.90 & 0.0395 \\
\hline 0.42 & 41.7 & 0.466 & 0.416 & 8.08 & 0.0404 \\
\hline 0.56 & 43.7 & 0.471 & 0.560 & 11.5 & 0.0576 \\
\hline
\end{tabular}

$I_{\mathrm{SC}}:$ short circuit photocurrent density; $V_{\mathrm{OC}}:$ open circuit voltage; $F F$ : fill factor; $P_{\max }:$ maximum power; $\eta$ : photoelectric conversion efficiency under $20 \mathrm{~mW} \mathrm{~cm} \mathrm{~cm}^{-2} \mathrm{UV}$ light source. 